\title{
A New Millennium
}

Perhaps no recent event has given so much credence to the social constructivist point of view as the decision, agreed by billions throughout the world, that the new millennium began on 1 January 2000. Our forebears a century ago knew that 1900 was the last year of the nineteenth century, 1901, the first year of the twentieth. Against all the facts, and the consequences of a little rational reflection, we are now in a new millennium. So be it.

The last issue of Medical History of 1999 marked another, more modest, but more precise, transition. With that issue, Vivian Nutton and I completed our twentieth year as co-editors of the journal. We inherited from the late Edwin Clarke a journal that had gone some way towards modernity and professionalism. We hope that during the past two decades we have completed the transition. We have regularized the peer-review process, extended the range of book reviewers and tried to ensure that the journal reflects the best of the discipline, while encouraging articles from authors with a wide range of backgrounds and expertise. Our own complementary areas of interest helped us from the beginning to divide our responsibilities, and over the years we have developed an efficient method of editing the journal. We certainly would not have lasted so long without the loyal help of our assistant editors, Jean Runciman, Christine Stevenson and Caroline Tonson-Rye.

Now, Vivian Nutton has taken the opportunity of a sabbatical in the United States to step down, or, rather up, since he now joins our House of Lords, the Board of Editors, where he will still be available to help with papers and book reviews which fall within his area of expertise. He declined the epithet of Editor Emeritus. I am joined as co-editor by my colleague Anne Hardy, who will be known to our readers as an author and book reviewer, and who has given much support over the years as a fair and efficient referee of articles. We intend to maintain the same high standards that Vivian Nutton has always espoused and to take the journal some ways at least into the new millennium.

W F Bynum 